Vázquez-Miraz, P. (2019). El tratamiento de la presunción de inocencia de un parricida en las primeras crónicas informativas de la prensa digital española. Revista de Antropología y Sociología: VIRAJES, 21(1), 181-195. DOI: 10.17151/rasv.2019.21.1.8

\title{
El tratamiento de la presunción de inocencia de un parricida en las primeras crónicas informativas de la prensa digital española
}

\section{PEDRO VÁZQUEZ MIRAZ*}

Recibido: 11 de febrero de 2019

Aprobado: 10 de mayo de 2019

Artículo de Investigación

\footnotetext{
* Doctor en Ciencias Sociales y del Comportamiento por la Universidad de La Coruña. Profesor de planta del programa de psicología de la Universidad Tecnológica de Bolívar (Colombia). Cartagena, Colombia. E-mail: pvasquez@utb.edu.co. (1) ORCID: 0000-0002-5801-1728. Google Scholar
} 


\title{
Resumen
}

El objetivo del presente artículo es el de analizar el tratamiento informativo que dan los medios de comunicación digitales al principio de presunción de inocencia y cómo se maneja el anonimato de los principales sospechosos en las primeras crónicas informativas. Esta meta se ha alcanzado por medio del estudio de contenido de distintas noticias de periódicos digitales de España relacionadas con el asesinato de un niño de 11 años por su propio padre en la localidad de Oza (Galicia, España) en mayo del año 2017, tras haber sido éste detenido por las autoridades policiales como principal sospechoso de este crimen. Los resultados revelaron que la mayoría de las piezas periodísticas revisadas no respetaron el principio jurídico de presunción de inocencia por lo que se ha evidenciado que el poder mediático juzga de antemano a los sospechosos de estos delitos haciendo pública su fisionomía.

Palabras clave: comunicación, prensa, periodismo digital, violencia infantil, identidad.

\section{The presumption of innocence treatment of a parricide in the first informative chronicles of the Spanish digital press}

\begin{abstract}
This article aims at analyzing the informative treatment that the digital media give to the principle of presumption of innocence and how anonymity of the main suspects is handled in the first informative chronicles. This objective was achieved through the study of the content of different news of digital newspapers in Spain related to the murder of an 11-year-old child by his own father in the town of Oza (Galicia, Spain) in May 2017, after the police authorities arrested him as the main suspect in this crime. The results revealed that most of the reviewed journalistic pieces did not respect the legal principle of presumption of innocence, so it has been shown that the power of media judges the suspects of these crimes beforehand by making their physiognomy public.
\end{abstract}

Keywords: communication, press, digital journalism, child violence, identity. 


\section{Introducción}

$\mathrm{E}$ 1 día 07/05/2017, en la ciudad española de La Coruña (Galicia), una madre denunció ante la policía la desaparición de su hijo, al no haber sido devuelto por su padre al punto de encuentro familiar estipulado tras finalizar el permiso de fin de semana, un período temporal en el que el otro progenitor podía estar con el menor legalmente. Tras ser el padre localizado y arrestado un día después, en un hostal de esta misma localidad por las fuerzas de seguridad como sospechoso de la desaparición, este finalmente confesó ante las autoridades el asesinato de su hijo y guio a la policía a un bosque de un municipio cercano (Oza), donde se encontró finalmente el cadáver del menor.

El asesinato de este niño de once años, cometido por su propio progenitor: un varón de mediana edad que llevaba separado de la madre del menor siete años, mientras disfrutaba de este permiso legal que le permitía estar con su hijo, abrió el debate sobre la defensa de la presunción de inocencia, pues aunque el padre rápidamente reconoció sus actos delictivos, en el momento en que fue detenido y grabado por los medios, aún no estaba probado judicialmente que él fuera culpable del parricidio, y en estos contextos es lógico plantearse que también se pueden presentar situaciones de instrumentalización a través de la manipulación informativa (Álvarez, 2017).

Los periódicos (digitales y/o impresos), a pesar de la grave crisis en la que se encuentran actualmente (Vázquez-Miraz, 2017), aún mantienen en la sociedad "la imagen preconcebida de seriedad y baluarte de objetividad [pues] la prensa [es] el soporte periodístico que más tiempo dedica a la elaboración de las noticias y que ha virado a un papel más reflexivo que instantáneo" (Zurbano y Liberia, 2014, p. 134); siendo por lo tanto interesante conocer el modo en el que se confeccionan en los medios de comunicación españoles las noticias informativas que están relacionadas con la violencia intrafamiliar extrema.

En el ámbito periodístico se ha abierto un interesante debate entre diferentes especialistas sobre si en el género periodístico de la crónica de sucesos debe primar más la objetividad y rigurosidad de la información tratada, conseguida por medio de la sobria recopilación y transmisión de los acontecimientos o si, por el contrario, debe tener un mayor peso en este tipo de noticias el análisis y la veloz interpretación de la realidad (Peris, 2016), pues "las noticias relacionadas con los procesos judiciales, especialmente 
los que se desarrollan en el ámbito penal, suscitan un creciente interés informativo ${ }^{1 \prime \prime}$ (Orenes, 2014, p. 121).

En las situaciones en las que el hogar familiar sufrió una ruptura de pareja, todos los agentes pueden ser objeto de conductas hostiles y agresivas (Hurtado, Ciscar y Rubio, 2004), pues están en juego muchos aspectos económicos y emocionales $\mathrm{y}$, a veces, llegar a acuerdos que contenten a las dos partes, como en el reparto de los bienes o la guarda y custodia de los hijos, es complicado. En estos entornos, los menores de edad suelen ser el eslabón más débil de la cadena familiar, pues ellos son demasiado pequeños para entender lo que les rodea y son los primeros en sufrir los cambios que afectan a su vida cotidiana; considerando también lo dicho por Horno (2016) respecto a que los niños y niñas también son víctimas de la violencia de género ejercida sobre sus madres. Sin caer en los alarmismos de los grupos más conservadores, en palabras de Wilson (como se citó en Gómez-Durán y Becoña, 1988), una característica traumática puede tener consecuencias muy graves pues la aparición de respuestas violentas es mucho más frecuente, siendo la disputa por guarda y custodia de los hijos una situación que favorece la aparición de este tipo de conductas.

La suma de todos estos múltiples factores influye notablemente en cómo los medios dan informaciones de asesinatos de menores de edad y/o jóvenes por miembros de su familia o de su círculo personal por simple venganza para perjudicar en lo más profundo a la otra parte de una vigente (o no) relación sentimental, asumiendo Peris (2013) que el asesinato de los hijos por sus padres tiene como objetivo el de maltratar psicológicamente a las exparejas, debiéndose considerar estos actos como violencia machista y/o de género. Si bien, estas interpretaciones nunca nos deben hacer olvidar el concepto jurídico de presunción de inocencia, pues como afirma Barata (2009):

La presunción de inocencia es un principio fundamental de la justicia y un signo de civilización, de ahí la importancia de que la actividad periodística sea respetuosa con su cumplimiento y ayude a su entendimiento social, pues entenderla y aplicarla es la primera regla de la cultura de la legalidad. (p. 221)

Antecedentes mediáticos parecidos al estudiado como el Caso Bretón (Cabrero, 2012), mostraron que la frágil frontera entre la prensa seria y la prensa sensacionalista española es cada vez es más difusa (Redondo-García, 2013). Por lo tanto, se asume como imperativo el proteger en los medios de

\footnotetext{
${ }^{1}$ La atracción del público por las noticias de sucesos puede ser explicada en parte por las grandes diferencias entre los tiempos periodísticos y los judiciales (Puebla y Lozano, 2014).
} 
comunicación tanto la imagen personal de los supuestos delincuentes como la de los fallecidos, pues se recuerdan nítidamente pasados sinsentidos mediáticos como lo acontecido con el asesinato de la niña Asunta Basterra ${ }^{2}$ (Torres, 2016), al haberse presentado inicialmente, a todo el país, imágenes de la menor y de sus progenitores sin ningún pudor en televisiones y diarios.

\section{Metodología}

El objetivo de este artículo fue revisar la praxis periodística de una serie de productos informativos de gran impacto emocional, como las noticias relacionadas con asesinatos de menores de edad a causa de sus propios familiares, para así determinar si la presunción de inocencia es respetada o no en los medios de comunicación de España y Galicia, centrándose específicamente en los medios digitales que narraron la detención del denominado "parricida de Labañou ${ }^{3}$ ". Estos fueron los primeros reportes en ser presentados a la sociedad, ya que aparecieron inmediatamente después de la detención del progenitor (ocurrida en un hostal de la ciudad de La Coruña, cercano a la vivienda del sospechoso).

Para realizar tal fin, se llevó a cabo un análisis comparativo de corte cualitativo en el que, en primer lugar, se observó el enfoque general dado en seis crónicas informativas realizadas a inicios de mayo del año $2017^{4}$ por medio de sus titulares y entradillas. Posteriormente, se revisó (además de la presencia del nombre y los apellidos del presunto asesino en estos medios) la existencia de una serie de factores que se han considerado sumamente relevantes para la causa judicial, tales como las denuncias previas de la ex-mujer por malos tratos, la aparición del arma homicida, los datos del barrio donde vivía el sospechoso (asociado históricamente con la delincuencia y la inseguridad), su situación laboral (estando el progenitor en el momento del crimen desempleado) y posibles atenuantes (como la existencia de problemas de salud mental).

\footnotetext{
${ }^{2}$ Caso mediático de gran relevancia nacional ocurrido en el año 2013 en la ciudad gallega de Santiago de Compostela en el que los padres de una niña adoptada fueron acusados por su asesinato premeditado (Seguí, 2016).

${ }^{3}$ Denominación informal realizada por los medios de comunicación ante este asesinato. El nombre del crimen se asoció al barrio de la ciudad de La Coruña donde vivía el sospechoso y, casualmente, ni se relacionó con el barrio aledaño donde el padre fue detenido (San Roque de Afuera) ni con el lugar del crimen (Oza).

${ }^{4}$ Estas informaciones fueron plasmadas en los principales medios digitales locales de la ciudad de La Coruña (El Ideal Gallego, La Opinión de A Coruña), regionales (La Voz de Galicia) y nacionales (El País, El Mundo, $A B C)$ de España.
} 


\section{Resultados}

La presentación de los datos fundamentales del detenido en estas primicias informativas ha variado significativamente en función del medio que ha sido revisado (Tabla 1) siendo el diario nacional $A B C$ y el local El Ideal Gallego los únicos agentes que no presentaron el nombre del acusado en sus informes.

Tabla 1. Datos presentados del detenido en los distintos medios de comunicación

\begin{tabular}{lllllll}
\hline $\begin{array}{l}\text { Datos } \\
\text { presentados del } \\
\text { acusado }\end{array}$ & $\begin{array}{l}\text { El } \\
\text { País }\end{array}$ & El Mundo & $\begin{array}{l}\text { Diario } \\
\text { ABC }\end{array}$ & $\begin{array}{l}\text { LaVozde } \\
\text { Galicia }\end{array}$ & $\begin{array}{l}\text { La Opinión } \\
\text { de A } \\
\text { Coruña }\end{array}$ & $\begin{array}{l}\text { El Ideal } \\
\text { Gallego }\end{array}$ \\
\hline $\begin{array}{l}\text { Nombrey apellidos } \\
\text { Posibilidad de }\end{array}$ & Sí & Sí & No & Sí & Sí & No \\
$\begin{array}{l}\text { identificación } \\
\text { visual }\end{array}$ & Sí & Sí & Sí & Sí & Sí & No \\
\hline $\begin{array}{l}\text { Existencia de } \\
\text { problemas mentales }\end{array}$ & Sí & No/Sí & No & Sí & Sí & No \\
\hline $\begin{array}{l}\text { Barrio de } \\
\text { residencia }\end{array}$ & No & Sí & Sí & Sí & Sí & No \\
\hline $\begin{array}{l}\text { Situación laboral } \\
\text { No }\end{array}$ & No & No & Sí & No & No \\
\hline $\begin{array}{l}\text { Antecedentes de } \\
\text { malos tratos }\end{array}$ & Sí & Sí & Sí & Sí & No & No \\
\hline $\begin{array}{l}\text { Arma homicida } \\
\text { utilizada }\end{array}$ & Sí & Sí & No & Sí & No & No \\
\hline
\end{tabular}

Fuente: Elaboración propia.

El periódico más importante de España, El País, propiedad del Grupo Prisa (Vázquez-Miraz, 2017), en su página web transmitió el nombre e iniciales de los apellidos del agresor, estando acompañando la crónica escrita con un vídeo en el que, si bien inicialmente aparecía la imagen estática del padre pixelada, al realizar el visionado de este elemento informativo (distribuido por las agencias de noticias EFE y Atlas) se podía observar perfectamente la cara del detenido (Imagen 1). Los autores de esta información, Huete, Pontevedra y Vizoso (2017), destacaron en su escrito la ausencia de antecedentes psiquiátricos del progenitor, habiendo presentado una descripción de la familia, de la madre y de su entorno más cercano en vez de tratar detalles individuales del agresor. 


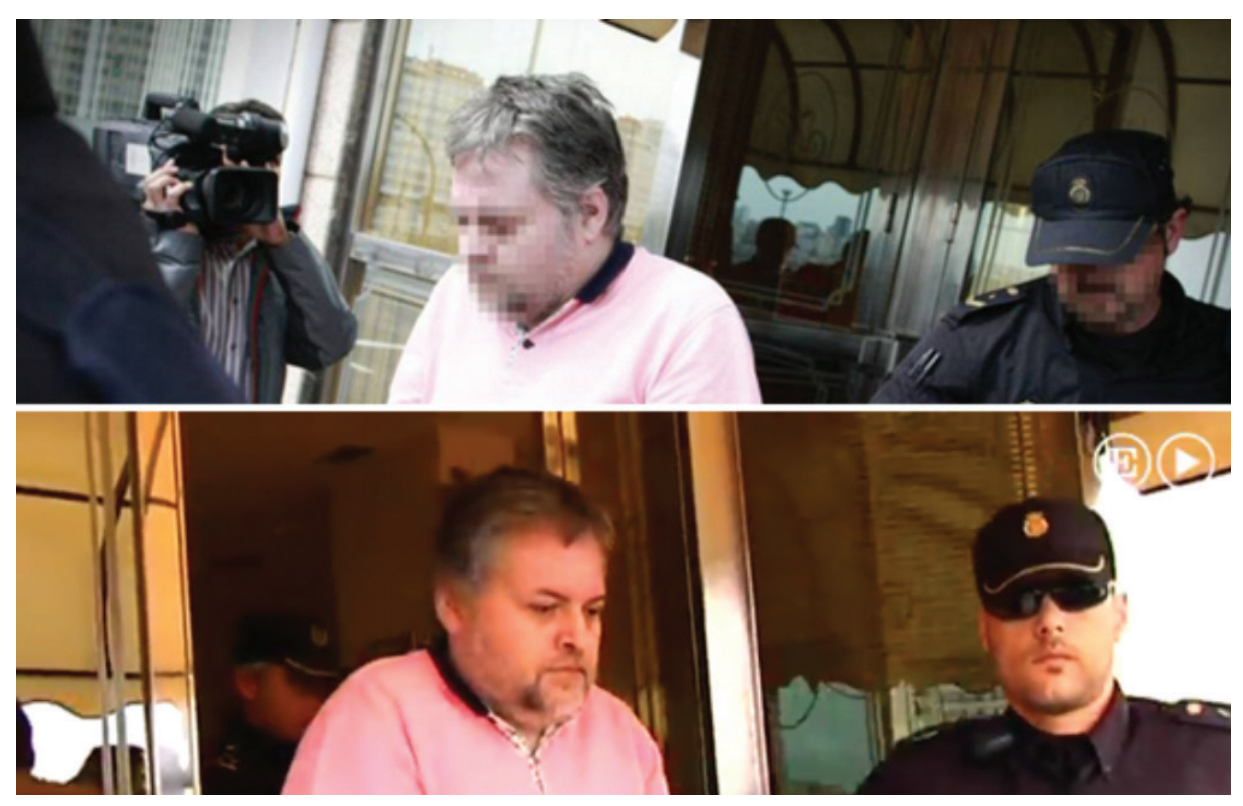

Imagen 1. Foto y video de la detención del principal sospechoso.

Fuente: Huete et al. (2017)

El hombre, que no tiene antecedentes psiquiátricos, tuvo una orden de alejamiento con respecto a la madre del menor que estuvo en vigor hasta 2013. Pero actualmente no había ningún tipo de medida contra Marcos M.M.

Eran vecinos de A Coruña aunque la familia del detenido es originaria de Oza y todavía residen en el lugar varios parientes. El pequeño estudiaba en un centro de la capital provincial, el colegio San Francisco Javier, en la zona de Cuatro Caminos. La madre es la conserje del centro educativo. Tanto ella como su hijo eran conocidos y queridos y el colegio se ha sumido en un estado de conmoción esta mañana. (Huete et al., 2017, párr. 4-5-6)

Respecto el titular y subtítulo de la noticia, inicialmente divulgada a las 14:21 y posteriormente ampliada a las 19:18 (hora española) del 9/05/2017, el primer elemento se centró en la detención del padre y el fallecimiento del menor "Detenido un hombre en A Coruña por la muerte de su hijo de 11 años en una visita", mientras que la entradilla enfocaba su interés periodístico en la denuncia inicial de la madre al no haberse devuelto al niño en el horario estipulado y en la arma homicida usada: “La madre denunció su desaparición cuando el padre no se lo devolvió. 
El niño fue golpeado en la cabeza y la policía busca una pala como supuesta arma".

El diario El Mundo en su informe [creado por Puga (2017) a las 14:15 y actualizado a las 17:49 del 9/05/2017], utilizó un similar titular que su competidor "Detenido un hombre por la muerte de su hijo de 11 años en A Coruña" centrándose el subtitular en la no devolución del infante y en una anterior orden de alejamiento del acusado hacia su ex-mujer: "La madre denunció que el padre no se lo había devuelto tras un permiso. El hombre tuvo una orden de alejamiento hasta 2013 pero ahora no tenía en vigor ninguna medida".

El padre, que se encuentra en la comisaría de policía de A Coruña, es un vecino de la ciudad herculina de 43 años de edad y cuya identidad responde a las iniciales de M.J.M.M. En la actualidad no había ningún tipo de medida ni orden de alejamiento contra el individuo detenido, que presenta problemas psiquiátricos (Puga, 2017).

El supuesto parricida, Marcos Javier Miras Montánez, de 42 años, había pasado el fin de semana con el niño y debía entregarlo a su ex pareja, de quién llevaba años separado y había tenido una orden de alejamiento, en un punto de encuentro. Además de no dejar al niño, no dio señales de vida y tampoco regresó a su casa en el barrio coruñés de Labañou, de modo que la Policía tardó horas en dar con su paradero. Finalmente, fue localizado escondido en un hostal. (Puga, 2017, párr. 2)

El Mundo presentó un similar material audiovisual, con las mismas incongruencias que el video de El País; la autora afirmó, primero, la existencia de los problemas psiquiátricos del progenitor (informe de las 14:15) para posteriormente transmitir una probabilidad: "El hombre podría estar en tratamiento psiquiátrico"; la misma periodista cayó en más contradicciones al describir la edad y el nombre del padre, pues inicialmente reveló solo sus iniciales para finalmente escribir su nombre completo.

çPor su parte, el titular "Detenido el padre del niño hallado muerto en un monte de Oza, en La Coruña" y subtítulo "La madre, separada del progenitor, alertó cuando el pequeño no le fue devuelto. El cadáver se encontraba en un monte" fueron los escogidos por la edición digital del periódico $A B C$, los cuales siguieron la misma orientación que sus pares habiendo presentado el mismo soporte visual con sus contraindicaciones sui generis. La descripción del progenitor en este medio, apenas se diferenciaba del resto de competidores:

El padre del menor reside en el barrio coruñés de Labañou y hasta el año 2003 tuvo una orden de alejamiento de su expareja, que lo 
denunció por amenazas. En concreto existen dos denuncias contra el detenido presentadas por su exmujer, ninguna de ellas reciente. Una de 2008 que finalizó con una sentencia condenatoria por un delito de coacciones. Otra denuncia de 2013 por amenazas a través de las redes sociales, fue sobreseída al no ser posible acreditar quién fue el autor de los hechos denunciados. (ABC, 2017, párr. 4)

El periódico regional La Voz de Galicia empleó parecidos enunciados para comentar este acontecimiento siendo el título "Detenido en A Coruña el padre del niño hallado muerto en Oza-Cesuras" y "La madre había denunciado su desaparición tras no serle devuelto el pequeño, que estaba con su padre. Fue él quien llevó a la policía hasta donde estaba el cadáver" como títulos principal y secundario, respectivamente.

Vecino del barrio coruñés de Labañou, nacido en 1974, que ha sido identificado con las iniciales M. J. M. M. Es electricista, pero en estos momentos se encuentra sin trabajo (...). El hombre fue denunciado, según el Tribunal Superior de Xustiza de Galicia, hasta en dos ocasiones por la madre del menor. La primera, interpuesta en el 2008 finalizó con una sentencia condenatoria por un delito de coacciones. La segunda, del 2013, por amenazas a través de las redes sociales, fue sobreseída al no resultar posible acreditar quién fue el autor de los hechos denunciados. (M.V., E.M. y J.M.P., 2017, párr. 4-5)

Este medio, a diferencia de otros rivales, mantuvo una mínima coherencia en el tratamiento de los datos audiovisuales, pues en ningún momento intentó respetar la presunción de inocencia del detenido, ya que jamás ocultó en sus informaciones el rostro del padre del menor, ni en las fotografías ni en los videos utilizados (estos últimos realizados por $V$ Televisión, empresa hermana del periódico); centrándose el periódico digital en la descripción del presunto parricida en las pasadas denuncias de la madre, su situación laboral y el barrio en el que este residía.

La Opinión de A Coruña mantuvo una estructura similar al resto de diarios en su perspectiva periodística, habiendo usado una escueta y neutra entrada para introducir la noticia (titular: "Detenido en A Coruña por el asesinato de su hijo de once años" y entradilla: "La madre había denunciado su desaparición después de que el padre no se lo entregara el domingo":

Un vecino de Labañou ha sido detenido como presunto autor del asesinato de su hijo, de once años, cuyo cadáver fue encontrado en una casa abandonada de la zona de Oza-Cesuras anoche, según han 
informado fuentes de la investigación. Fue el propio padre, de iniciales M.J.M.M. y de unos 42 años, quien indicó a la Policía Nacional a dónde había llevado el cuerpo de su hijo. (Mosquera, 2017, párr. 1)

Este medio, en la presentación inicial del hecho noticiable relatado, fue uno de los escasos diarios que no permitió que la imagen del acusado se viera a la luz pública, no presentando foto alguna del acusado (Mosquera, 2017), si bien en crónicas posteriores sí se ilustró la información con fotografías difuminadas y videos en el que el acusado tenía su rostro perfectamente visible (Mosquera y Pérez, 2017).

Finalmente, El Ideal Gallego trazó una línea completamente diferente al de sus competidores, pues aunque su titular "Detenido el padre del niño hallado muerto en un monte de Oza-Cesuras (A Coruña)" y entradilla "El padre del niño de 11 años de edad hallado muerto en la tarde-noche del lunes, después de haber denunciado su madre su desaparición, permanece detenido en dependencias policiales", coincidieron parcialmente con los demás textos revisados, este diario digital dirigió la noticia exclusivamente en la información descriptiva más relevante de la víctima:

El padre del niño de 11 años de edad hallado muerto en la tarde-noche del lunes, después de haber denunciado su madre su desaparición, permanece detenido en dependencias policiales. Así lo han confirmado a Europa Press fuentes próximas a la investigación, que han señalado que la Policía Nacional mantiene abierta una investigación para esclarecer los hechos.

El cuerpo del menor fue localizado en una zona de monte del municipio coruñés de Oza-Cesuras en la tarde-noche del lunes, si bien la desaparición del niño había sido denunciada en A Coruña. (Redacción El Ideal Gallego, 2017, párr. 1-2-3)

Un día más tarde, este mismo periódico ampliaba el anterior teletipo, pues El Ideal Gallego fue el diario digital del total de estudiados que no publicó el día de la captura del progenitor su respectiva crónica, esperando al día siguiente para informar más detalladamente a sus lectores (A.P, 2017). Al no haber usado videos y anonimizar al presunto criminal en las fotografías utilizadas, este fue el único noticiero que mantuvo una coherencia total en función a la presunción de inocencia de un individuo hasta la existencia de una sentencia judicial firme que determine la culpabilidad o inocencia del acusado. 


\section{Discusión de resultados}

Si bien es plenamente vigente la afirmación de Fernández (como se citó en Molina, 2016) sobre la tendencia que tienen los periodistas a la hora de plasmar noticias buscando "las emociones, capaces de despertar sentimientos en el público debido a que la información y el entretenimiento se entremezclan (...) [pues así se] hace subir el número de lectores, oyentes o telespectadores" (p. 184); todos los periódicos analizados han introducido en sus titulares la relación directa de parentesco entre el presunto agresor y víctima, primando en los subtítulos la denuncia realizada por la madre anteriormente por la desaparición del niño, siendo lógica la presencia de diferencias no analizadas en función del espacio y situación que se la ha dedicado a estas primeras noticias en las webs de los medios nacionales, regionales y locales visitadas, al ser también diferentes los lectores potenciales a los que estos productos se dirigen.

A pesar de la aparente uniformidad de los titulares e informes analizados, se han observado interesantes matices entre estos diarios. El País, El Mundo y La Opinión de A Coruña prefirieron centrar en sus titulares el rol de la víctima a través del importante término emocional "hijo", mientras que los restantes medios decidieron destacar en sus titulares el papel activo del padre. Interesante también fue la mención de la mayoría de periódicos digitales de los antecedentes por malos tratos que tuvo el señor en el pasado respecto su antigua pareja, pues si bien no se puede hacer una asociación causa-efecto de este delito con tales elementos, a nivel jurídico podría ser usado en contra del acusado.

Los titulares revisados también se han diferenciado respecto el punto geográfico que requería la atención de los lectores. Mientras que El País, El Mundo y La Opinión de A Coruña centraron los titulares en el lugar en el que se produjo la detención del progenitor, el $A B C$ y El Ideal Gallego orientaron sus titulares en el lugar donde se encontró el cuerpo sin vida del menor, siendo La Voz de Galicia el único periódico que presentó en su titular ambos espacios.

También fue llamativa la importancia que los medios dieron al barrio en el que residía el detenido cuando se cometió el asesinato, Labañou, incluyendo los diarios nacionales, ya que para sus lectores principales esta información sería prácticamente baladí al no conocer nada de esta específica barriada. Este particular interés por el origen vecinal del presunto parricida

\footnotetext{
${ }^{5}$ Distrito vecinal de la ciudad de La Coruña de estrato medio, que en el pasado tenía una mala fama al ser meramente conocido por sus habituales peleas juveniles y otras problemáticas sociales (Malvido, 2016). Esta nefasta imagen bien la conoce el autor por sus propios orígenes familiares.
} 
se evidenció más al ver cómo la prensa gallega y española trató homicidios parecidos, tales como la muerte de dos gemelos por parte de su padrastro en esta misma ciudad en el año 2011 (Martínez, 2011; Nebreda, 2011; Vázquez y Espiñeira, 2011) o el ya mencionado caso Asunta, en el que los progenitores eran de clase alta (Seguí, 2016) y el específico lugar de residencia de los sospechosos no tuvo tanta importancia para los periodistas.

Los posibles problemas psiquiátricos del padre del niño fueron una de las partes de la noticia donde más divergieron las informaciones de los distintos medios de comunicación analizados. Desde la negación absoluta que defendió El País, el cambio de postura en las diferentes versiones de El Mundo $0^{6}$ la calculada omisión que hizo de este elemento $A B C$ y El Ideal Gallego, hasta la certeza de que el padre sufría problemas de salud mental como revelaron La Opinión de A Coruña y La Voz de Galicia.

Menos disimilitudes se encontraron en los datos que hacían referencia al nombre personal del detenido, pues a excepción de una segunda versión del diario El Mundo, el resto de medios se limitaron a señalar las iniciales del acusado (La Voz de Galicia, La Opinión de A Coruña), el nombre y las iniciales de los apellidos del sospechoso (El País) o no dar información alguna ( $A B C$, El Ideal Gallego); si bien en días siguientes, la mayoría de medios de comunicación dieron sin ningún pudor el nombre completo del presunto parricida.

\section{Conclusiones}

La mayoría de los medios de comunicación revisados no mantuvieron la presunción de inocencia del detenido con base en que, o bien habían transcrito en sus textos el nombre completo del sospechoso, o bien habían utilizado soportes audiovisuales que permitían identificar al progenitor en sus noticias; siendo paradójico que El Ideal Gallego, el informante local más escueto en sus primeras informaciones y el de menores recursos económicos, fuera el que ha mantenido plenamente una posición ética coherente al no revelar en ningún momento la identidad del acusado.

En definitiva, se ha encontrado una total incongruencia entre los materiales utilizados para complementar las respectivas crónicas informativas a la hora de mantener el anonimato del principal sospechoso, algo que evidencia las malas prácticas de los profesionales del periodismo español y recuerda a otros casos mediáticos ya mencionados de este país. La presencia (o no) de imágenes pixeladas del padre del niño

\footnotetext{
${ }^{6}$ En un lapso de cinco horas, el periodista se contradijo a sí mismo respecto la ausencia o presencia de enfermedades mentales que padecía (o no) el sospechoso principal.
} 
fallecido acompañada de videos en que su rostro sí se puede identificar de forma irremediable es una incomprensible situación que no tiene justificación alguna.

El rechazar con vehemencia los denominados "juicios paralelos" (Montalvo, 2012; Guzmán-Fluja, 2018) y "circos mediáticos" (Manes, 2017) no nos impide reconocer nuestras propias limitaciones morales, pues aunque creemos firmemente en la justicia y las instituciones legales (a pesar de sus múltiples carencias), cierto es que en muchas ocasiones nos es muy doloroso el apelar a esta presunción de inocencia en casos como el que se ha analizado $u$ otros similares; pero esto no es impedimento para que aceptemos la máxima judicial de que todo individuo es inocente hasta que se demuestre lo contrario, negándole siempre la validez a cualquier argumento ad populum, por muy bien intencionado que este sea (Angulo, 2019). Como afirma Ovejero (2017):

La globalización de todos los procesos sociales, incluidos los judiciales, exigen una mejor información pública sobre los casos que conocen los tribunales, en una más y mejor garantía del proceso. La presunción de inocencia sigue siendo, en ese sentido, un derecho útil, plenamente vigente y aplicable en la defensa de la dignidad de quienes, aún en fase preliminar, son objeto de persecución judicial o mediática. (p. 455)

Al igual que Barrero (2001), entendemos que los informadores tienen plena libertad de expresión para transmitir las noticias desde sus propias líneas editoriales, ya que los medios son empresas privadas y la información que ofrecen ha de ser rentable (Puebla y Lozano, 2014), pero estos dos criterios deben subordinarse siempre a la profesionalidad y a la ética de la profesión periodística. Tras lo expuesto se deduce fácilmente que son los propios medios de comunicación los que no tienen claro cómo han de tratar la presunción de inocencia, evidenciándose también que los medios de masas actuales juzgan de antemano a los principales sospechosos de impactantes asesinatos. El periodismo español lamentablemente no aprendió nada de los terribles errores cometidos en los casos Wanninkhof (Villalobos, 2016) o Aitana (Maciá-Barber y Galván-Arias, 2012).

\footnotetext{
${ }^{7}$ Concepto definido como la situación jurídico-social que se produce "cuando los medios de comunicación asumen un papel que está asignado constitucionalmente a los jueces y magistrados que integran el Poder Judicial del Estado" (Barrero, 2001, p. 173).
} 


\section{Referencias}

ABC. (2017). Detenido el padre del niño hallado muerto en un monte de Oza, en La Coruña. Diario ABC. Recuperado de http://www.abc.es/espana/galicia/abci-hombremata-hijo-11-anos-coruna-201705090905_noticia.html.

Álvarez, A. (2017). Violencia de género y manipulación mediática: el caso de Juana Rivas. En M. Cabrera y J.A. López. (Coord.), Comunicaciones IX Congreso Virtual sobre Historia de las Mujeres (39-48). Jaén, España: Archivo Histórico Diocesano de Jaén.

Angulo, M. (2019). Subjetividad y violación social. El caso de La Manada. Tropelías. Revista de Teoría de la Literatura y Literatura Comparada, 31, 86-96.

A.P. (2017). Detenido un vecino de Labañou por matar a su hijo de once años. Diario El Ideal Gallego. Recuperado de http://www.elidealgallego.com/articulo/coruna/ detenido-vecino-labanou-matar-enterrar-hijo-once-anos/20170509225801332860.html

Barata, F. (2009). La devaluación de la presunción de inocencia en el periodismo. Anàlisi: quaderns de comunicació i cultura, 39, 217-236.

Barrero, A. (2001). Juicios paralelos y Constitución: su relación con el Periodismo. Ámbitos: Revista internacional de comunicación, 6, 171-189.

Cabrero, Á. (2012). Personalidad psicopática y crimen (algunas reflexiones psicológicas, psiquiátricas, criminológicas y jurídico-penales a resultas del caso José Bretón). Foro, Nueva Época, 15(2), 125-155. DOI: http://dx.doi.org/10.5209/rev_FORO.2012.v15.n2.41489

Gómez-Durán, B.J. y Becoña, E. (1988). Estudios sobre actitudes sociales con muestras de la población gallega. A Coruña, España: Diputación Provincial de A Coruña.

Guzmán-Fluja, V.C. (2018). Juicios paralelos en las redes sociales y proceso penal. IDP. Revista de Internet, Derecho y Política, 27, 52-66.

Horno, P. (2006). Atención a los niños y niñas víctimas de la violencia de género. Intervención psicosocial, 15(3), 307-316.

Huete, C., Pontevedra, S.R. y Vizoso, S. (2017). Detenido un hombre en A Coruña por la muerte de su hijo de 11 años en una visita. Diario El País. Recuperado de http://politica. elpais.com/politica/2017/05/09/actualidad/1494315258_147095.html.

Hurtado, F., Ciscar, C. y Rubio, M. (2004). El conflicto de pareja como variable asociada a la violencia de género contra la mujer: consecuencias sobre la salud sexual y mental. Revista de psicopatología y psicología clínica, 9(1), 49-64. DOI: https://doi.org/10.5944/rppc. vol.9.num.1.2004.3967

Maciá-Barber, C. y Galván-Arias, M.Á. (2012). Presunción de inocencia y deontología periodística: el 'caso Aitana'. Revista Latina de Comunicación Social, 67, 362-393. DOI: http://dx.doi.org/10.4185/RLCS-2012-960

Malvido, G. (2016). Miniuniverso Labañou. Diario La Opinión de A Coruña. Recuperado de http://www.laopinioncoruna.es/coruna/2016/03/13/miniuniverso-labanou/1050346. html

Manes, V. (2017). La «vittima» del «processo mediatico»: misure di carattere rimediale. Diritto penale contemporaneo, 3, 114-128.

Martínez, A. (2011). Dos gemelos de 10 años, asesinados por su padrastro en La Coruña. Diario $A B C$. Recuperado de http://www.ABC.es/20110821/espana/ABCi-gemelosmuertos-coruna-201108211901.html

Molina, M.D. (2016). El Tratamiento de los Crímenes en la Prensa de Murcia. Análisis de Evolución y Estudio de los Asesinatos en La Verdad y La Opinión (1990-2014) (tesis doctoral). Universidad de Murcia, Murcia, España.

Montalvo, J.C. (2012). Los juicios paralelos en el proceso penal: ¿anomalía democrática o mal necesario? Universitas: Revista de Filosofía, Derecho y Política, 16, 105-125. 
Mosquera, M. (2017). Detenido en A Coruña por el asesinato de su hijo de once años. Diario La Opinión de A Coruña. Recuperado de http://www.laopinioncoruna.es/coruna/2017/05/09/ detenido-asesinato-hijo-once-anos/1179274.html

Mosquera, A. y Pérez, M. (2017). El niño de A Coruña fue asesinado a golpes. Diario La Opinión de A Coruña. Recuperado de http://www.laopinioncoruna.es/coruna/2017/05/09/ nino-once-anos-asesinado-coruna/1179321.html

M.V., E.M. y J.M.P. (2017). Detenido en A Coruña el padre del niño hallado muerto en OzaCesuras. Diario La Voz de Galicia. Recuperado de http://www.lavozdegalicia.es/noticia/ coruna/oza-cesuras/2017/05/09/detenido-coruna-padre-nino-encontradomuerto-ozacesuras/00031494311961847524321.htm

Nebreda, M. (2011). Detenido el padrastro de dos gemelos de 10 años presuntamente asesinados. Diario El Mundo. Recuperado de http://www.elmundo.es/ elmundo/2011/08/21/galicia/1313943567.html

Orenes, J.M. (2014). El control no jurisdiccional de los juicios en televisión por parte de las autoridades audiovisuales. Dilemata, 14, 121-140.

Ovejero, A.M. (2017). Protección del derecho a la presunción de inocencia. Teoría y Realidad Constitucional, 40, 431-455.

Peris, M. (2013). La despolitización de la violencia de género a través de la terminología. Asparkía, 24, 176-194.

Peris, M. (2016). Los medios de comunicación y la pedagogía sobre el significado de la violencia machista. Zer, 21(40), 13-30. DOI: http://dx.doi.org/ 10.1387/zer.16404

Puebla, B. y Lozano, V. (2014). Periodismo jurídico. El tratamiento informativo en prensa del caso 'Marta del Castillo' en los diarios El País y El Mundo. Fonseca, Journal of Communication, 8, 35-69.

Puga, N. (2017). Detenido un hombre por la muerte de su hijo de 11 años en A Coruña. Diario El Mundo. Recuperado de http://www.elmundo.es/sociedad/2017/05/09/59116c97e5fde a09278b4640.html.

Redacción El Ideal Gallego (2017). Detenido el padre del niño hallado muerto en un monte de Oza-Cesuras (A Coruña). Diario El Ideal Gallego. Recuperado de http://www. elidealgallego.com/articulo/a-coruna/detenido-padre-nino-hallado-muerto-monte-ozacesuras-coruna/20170509110630332805.html.

Redondo-García, M. (2013). El sensacionalismo y su penetración en la prensa española de calidad. El "caso McCann" en El País, El Mundo y ABC. Estudios sobre el Mensaje Periodístico, 19(1), 235-253. DOI: http://dx.doi.org/10.5209/rev_ESMP.2013.v19.n1.42519

Seguí, L. (2016). El enigma del mal. Madrid, España: Fondo de Cultura Económica de España.

Torres, P. (2016). El discurso periodístico y los procesos de criminalización. Una reflexión sobre el caso Asunta. Recuperado de http://hdl.handle.net/11441/50545

Vázquez, D. y Espiñeira, F. (2011). El autor de la muerte de los gemelos de A Coruña se ensañó con ellos. Diario $\mathrm{La}$ Voz de Galicia. Recuperado de http://www.lavozdegalicia.es/noticia/coruna/coruna/2011/08/22/autor-muertegemelos-coruna-ensano/0003_201108G22P2991.htm

Vázquez-Miraz, P. (2017). El fracaso del periódico Ahora, el ocaso de la prensa impresa española. Miguel Hernández Communication Journal, 8, 267-286.

Villalobos, G. (2016). De juicios paralelos a procesos mediáticos. Tratamiento informativo del derecho a la presunción de inocencia y roles periodísticos profesionales en un estudio de casos. Dolores Vázquez (2000-2001), Juan Enciso (2009) y Diego Pastrana (2009) (tesis doctoral). Universidad de Málaga, Málaga, España.

Zurbano, B. y Liberia, I. (2014). Revisión teórico-conceptual de la violencia de género y de su representación en el discurso mediático. Una propuesta de resignificación. Zer, 19(36), 121-143. 